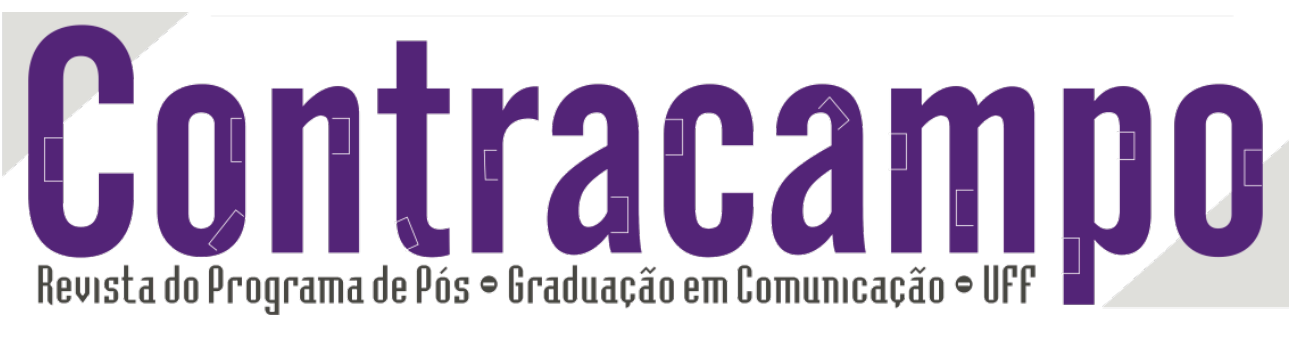

\title{
Os testemunhos de catástrofes nas revistas brasileiras: do medo individual à patemização midiática
}

\author{
The testimonies of disasters in Brazilian journals: \\ from individual fear to media pathemization
}

Márcia Franz Amaral Doutora em Comunicação pela Universidade Federal do Rio Grande do Sul, pós-doutora pela Universitat Pompeu Fabra, Barcelona, pesquisadora do CNPq, líder do Grupo Estudos de Jornalismo (CNPq), Professora do Programa de Pós-Graduação em Comunicação da UFSM

\section{PPGCOM}

\section{Edição 26/2013}




\section{Resumo}

O artigo faz uma reflexão sobre as especificidades dos acontecimentos catastróficos na atualidade e sua cobertura pela mídia e mostra como os discursos sobre as catástrofes se modificam ao longo do tempo. No discurso jornalístico atual, ressaltam-se os relatos das fontes testemunhais e de suas emoções, como o medo e a angústia. A pesquisa analisa a citação literal das fontes testemunhais nas matérias sobre a maior catástrofe brasileira, o deslizamento ocorrido na região serrana do Rio de Janeiro em janeiro e fevereiro de 2011, nas revistas Veja, Época e IstoÉ. Consideramos que a citação das fontes testemunhais integrou um determinado efeito patêmico, a partir do aporte teórico de Patrick Charaudeau.

Palavras-chave: Cobertura de catástrofes, fontes jornalísticas, emoção no jornalismo.

\section{Abstract}

The article reflects on the specificities of catastrophic events in the news and its coverage by the media and shows how the discourses on disasters are modified over time. In the current journalistic discourse, it is emphasized the reports of testimonial and emotional sources such as fear and anxiety. The research analyzes the literal citation of sources in articles about the greatest Brazilian catastrophe, the slippage occurred in the mountainous region of Rio de Janeiro in January and February 2011 in the magazines Veja, Epoca and IstoÉ. We believe that the citation of testimonial sources integrated a given patemic effect from the theoretical input of Patrick Charaudeau.

Keywords: Catastrophic coverage, journalistic sources, emotion in the journalism. 
A nalisamos o papel da emoção na manifestação de fontes testemunhais citadas na cobertura dos deslizamentos do Rio de Janeiro em 2011 nas três maiores revistas semanais de informação (Veja, Época e IstoÉ), num total de dez matérias (edições de janeiro e fevereiro). O trabalho trata, inicialmente, das catástrofes consideradas como "naturais" e suas coberturas midiáticas e, posteriormente, da análise do papel das manifestações das fontes testemunhais.

O campo jornalístico, no caso da cobertura de catástrofes, assenta-se nos campos científicos e políticos para esquadrinhar os riscos que envolvem a natureza, para explicar esses riscos e para construir sistemas de prevenção. Entretanto, cabe às fontes testemunhais relatar o ocorrido e ilustrar as matérias com suas histórias de vida. Pesquisas mostram que, anteriormente, quando pessoas eram atingidas por uma tragédia, relatava-se o caso de forma generalizada com a presença de alguns testemunhos anônimos. Hoje, as pessoas são apresentadas com nome, idade, profissão e aparecem como sendo vítimas da interrupção de uma vida cheia de felicidades e de projetos. (VAZ e ROLNY, 2010).

$\mathrm{O}$ artigo é parte de uma pesquisa mais ampla,intitulada Testemunhos e experts nos acontecimentos das catástrofes ambientais, financiada pelo CNPq, (Edital MCT/CNPQ 471283/2010-0) que analisa o papel das fontes jornalísticas na cobertura de catástrofes por parte das quatro revistas durante todo o ano de 2011. O trabalho mostra como cada fonte jornalística tem papéis específicos no caso do relato das tragédias. Às fontes especialistas, é atribuído um saber de conhecimento, uma representação racionalizada que buscar tornar o acontecimento inteligível. Elas têm papel destacado na cobertura das catástrofes, pois transcendem a experiência traumática propondo explicações para ela. As fontes autoridades têm sido insistentemente tensionadas tanto pelos jornalistas quanto pelos especialistascomo responsáveis pelos acontecimentos catastróficos. Enquanto isso, as fontes testemunhais descrevem os fatos e trazem a marca do sensível, da experiência, do vivido. Assim, o objetivo do trabalho é refletir sobre o papel da manifestação dos testemunhos nesta cobertura, especialmente no que elas têm de maior voltagem: o relato de suas emoções, especialmente o relato do medo. 
O medo é seguramente o mais sinistro dos muitos demônios que se aninham nas sociedades abertas de nossa época. Mas é a insegurança do presente e a incerteza do futuro que criam e alimentam o mais aterrador e o menos suportável de nossos medos. A insegurança e a incerteza, por sua vez, nascem de um sentimento de importância: não parecemos mais estar no controle [...]. (BAUMAN, 2008: 167)

Ao relato do medo, somamos o da angústia. Baseados em Delumeau (apud CHARAUDEAU E MAINGUENEAU, 2004), podemos afirmar que o temor, o espanto, o pavor ou o terror devem ser considerados como medo; já os sentimentos de inquietação, de ansiedade e de melancolia, devem ser considerados como angústia. A diferença está no fato de o medo incluir "um objeto determinado ao qual se pode fazer frente”, pois refere-se a algo conhecido. Já a angústia não possui nem conhece esse objeto, é "vivida como uma espera dolorosa diante de um perigo tanto mais temível quanto menos claramente identificado: é um sentimento global de insegurança" (DELUMEAU, 1989: 25). As declarações das testemunhas escolhidas pelas revistas para terem visibilidade manifestam estes dois sentimentos concomitantemente.

\section{O jornalismo e as catástrofes ambientais}

Nestrovski e Seligmann-Silva (2005) explicam que a palavra catástrofe vem do grego e significa "virada para baixo" (kata + strophé). É, por definição, um evento que provoca trauma, outra palavra grega, que significa "ferimento". E a principal característica do trauma é ser um estímulo demasiado grande para ser assimilado. Mas as catástrofes são percebidas de forma diferente pelos homens com o passar do tempo:

Las crisis y las catástrofes son construciones sociales. Las dimensiones que alcanzam cualquer conflito dependen única $\mathrm{y}$ exclusivamente de la transcendência que les confieram los seres humanos, y em esta operación los médios de comunicación juegan um rol de gran importância al transmitir uma serie de mensajes que contribuyen em la definicion del acontecimento. (LOZANO ASCÊNCIO, 2004: 79)

As catástrofes no passado tinham características bem diferentes das de agora: eram irremediáveis, pois o homem vivia sob seus desígnios e tinha o contato direto e presencial com o acontecimento; deixavam sequelas duradouras e a experiência permanecia na memória coletiva de várias gerações; a vida da comunidade era delimitada com "o antes e o depois" da catástrofe e as tragédias eram explicadas por 
meio de mitos e ritos, numa tentativa de dominar o inesperado (LOZANO ASCÊNCIO, 2004). A representação das catástrofes era mítica e os projetos para dominar as atividades inesperadas da natureza se manifestavam em rituais.

Se antes os homens estavam à mercê das catástrofes, hoje tentam obcecadamente submeter as catástrofes aos seus desígnios. As tragédias atuais são referenciáveis, predicáveis, antropocêntricas e tensionam os limites da ciência. Até as catástrofes autógenas, ocasionadas apenas pela natureza, têm uma interpretação antropológica. Lozano Ascêncio (2004: 86) afirma que a sociedade não é capaz de fazer uma representação em que não seja afetada diretamente. A natureza só existe na medida em que a sociedade é capaz de dominá-la. Atualmente, é no relato dos testemunhos que a catástrofe midiatizada se realiza.

As representações das catástrofes se modificam ao longo do tempo, auxiliam na construção de algumas crenças e paradigmas científicos e na destruição de outros. Para Lozano Ascêncio, a catástrofe subverte a ordem e o relato da catástrofe estabiliza a ordem. O momento mais importante é quando a interpretamos:

delimitar catástrofes es uma operación cognitiva que va más allá de la vigência espacio-temporal, evoluciona com el devenir histórico, por la que idea que se tiene de las catástrofes se determina según la época, y la época se caracteriza según sean las ideas que se tienen de las catástrofes". (2011: 1)

Para Lozano Ascêncio (2002), uma catástrofe só existe se destrói. O mais importante nela não é o que existe ou se sucede, mas o que transtorna e como os transtornos são percebidos, valorados e relatados publicamente. As causas das catástrofes são determinadas por suas consequências. O valor é dado pelo que é destruído e não pelo o que origina a destruição. Mede-se a catástrofe pela capacidade de alteração do entorno cotidiano e de "colocar al ser humano como la medida de todas las cosas, mientras que el orden ambiental permanece subeditado ante uma mentalidade antropocêntrica." (LOZANO ASCÊNCIO, 2004: 31). Conforme o autor, a catástrofe é um fenômeno cultural, não existe por si só na gênese de sua ocorrência. Adquire a catalogação de catástrofe quando suas consequências desequilibra as ordens, trajetórias ou permanências estabelecidas pela sociedade e cultura.

$\mathrm{O}$ acontecimento catastrófico constitui-se em experiência para aqueles que o 
viveram, mas, sobretudo, comporta crenças e visões sociais de mundo. Pode, assim, reproduzir, inaugurar ou modificar interpretações sobre o mundo, e, nesse movimento, mobilizar diferentes processos cognitivos e culturais. A mídia, especialmente o jornalismo, tem papel preponderante neste processo.

"Sin comunicación no hay catástrofe": a afirmação de Lozano Ascêncio (2004, p.22) resume o papel da cobertura jornalística. Aliás, para o autor, "la principal puerta de acceso a los médios de comunicación para el médio ambiente sigue siendo el desastre, la cruda imagen que garantisse el impacto del público.”(2004: 33). Como afirma Gomes (2004), o jornalismo "apresenta o mundo como ele deve ser visto" e a cobertura das catástrofes auxilia na interpretação do ocorrido e na produção de novos fatos relacionados.

As catástrofes são um fenômeno discursivo e cultural. Sua cobertura está presidida pela tendência ao catastrofismo, ao sensacionalismo e pela preponderância da imagem sobre a análise. Outra característica também chama a atenção: a personalização. As catástrofes midiáticas baseiam-se crescentemente no relato pormenorizado das vítimas. Esta individualização ocorre, entretanto, somente em relação aos testemunhos. $\mathrm{Na}$ apuração das responsabilidades pelas tragédias há um processo contrário, de despersonalização. Ponte (2004), citando Fowler (1991:15-16), afirma que a personalização é um recurso poderoso no trabalho jornalístico, mas tem limites. A

obsessão com pessoas serve de paliativo para contornar discussões sérias dos factores sociais e econômicos subjacentes, actuando como um aspecto de uma ideologia hegemónica de representação.[...]. Não bastam que existam as pessoas, é preciso que correspondam e se adequem ao molde cultural com que são pensadas. (PONTE, 2004: 126)

A emoção emerge neste processo. Não basta que o fato seja emocionante em si, é preciso carregar nas tintas de descrições individuais, de relatos parciais e envolventes. $\mathrm{O}$ discurso midiático busca boas vítimas que possam fazer o seu leitor, do conforto de sua leitura, compadecer-se com o que aconteceu (vítimas virtuais). Quando o testemunho fala de dores, cheiros e sentimentos como medo e angústia, dá o tom da veracidade, parece reproduzir a experiência imediata. Autores como Bourdieu (1998: 25) já mencionaram que a comunicação só tem êxito ao suscitar e ressuscitar experiências singulares, socialmente marcadas. Entretanto, a experiência, aparentemente fonte do 
sentido, configura-se numa rede discursiva com o papel de evidenciar a singularidade.

Como lembra Ponte (2004), a cobertura acentua o lado comum da vítima, como descrições de particularidades arbitrárias ou detalhes biográficos, eliminando ou limitando a intervenção humana na ação por uma diversidade de processos discursivos. Alguns acidentes são narrados pela mídia como história da fatalidade, do inexplicável, numa lógica melodramática marcada pela retórica da autenticidade. .

Este enquadramento sofre também influência do que denominamos de lógica do "ao vivo" - é a contaminação de todo o jornalismo com a lógica do ao vivo e do tempo real (da TV e da Internet) em que pouco se apura, tudo se especula. A reunião de especialistas ao vivo é um exemplo desta tentativa de procurar explicações enquanto o fato ainda se desenrola. O Jornal Nacional, por exemplo, foi apresentado ao vivo, "do lugar da tragédia" no episódio do deslizamento no Morro do Bumba, em Niterói. É sintomático desta política de alimentar a ansiedade gerada pelo fato e de manter o tom da gravidade com o lamento das testemunhas (sejam vítimas ou não).

\section{Testemunhos, emoção e efeitos de patemização}

Os testemunhos funcionam como sinais de marcação de realidade. Trata-se de um exercício de referencialidade, de remetência a um real de "suposta plenitude" (GOMES, 2000: 25). Parafraseando a autora, podemos afirmar que os procedimentos discursivos de referencialidade são encarnados pela emoção.

O testemunho auxilia na reconstrução discursiva do acontecimento, mas é representado como alguém que não tem a noção do todo. Para Lage, o testemunho

é normalmente colorido pela emotividade e modificado pela perspectiva: pode-se testemunhar uma guerra sem presenciar uma batalha, assistindo a um pedaço de uma (dificilmente se terá acesso ao todo), ou vendo várias; do lado do vencedor ou do vencido; identificando-se com as vítimas ou com os agressores. [...] De modo geral, o testemunho mais confiável é o mais imediato. Ele se apóia na memória de curto prazo, que é mais fidedigna, embora eventualmente desordenada e confusa; para guardar fatos na memória de longo prazo, a mente os reescreve como narrativa ou exposição, ganhando em consistência o que perde em exatidão fatual. (LAGE, 2001: 12) 
Conforme Rodrigues, o testemunho é a comunicação "que existe entre alguém que teve a experiência directa e imediata de um acontecimento ou de um fenômeno que a comunica a outra pessoa que não teve a mesma experiência directa e imediata"(1997: 01).Assim, cabe àquelas fontes destituídas de poder e de conhecimento dar o tom da história, torná-la verdadeira e interessante.

A matéria de Veja (23/02/2011) intitulada Luto na serra fluminense, a tragédia continua dentro dos corações é um exemplo de como os testemunhos são utilizados. A matéria abre com a afirmação "O advogado Samuel Guerra e Silva, de 43 anos, ainda chora muito." E assim, utiliza-se dos testemunhos para relatar detalhes sobre as diversas vítimas cujas histórias aparecem uma a uma. Assim também ocorreu exaustivamente com os discursos sobre o caso dos mineiros do Chile. Cada mineiro se tornou um personagem único e suas emoções foram exaustivamente exploradas pela cobertura jornalística. $\mathrm{O}$ mundo inteiro conhecia a história de cada um e o que significava para sua vida particular se salvar.

Passamos então a observar as sequências discursivas retiradas da manifestação das fontes testemunhais que remetem a emoções como o medo e a angústia, para refletirmos qual é o seu papel na cobertura jornalística.

\begin{tabular}{|l|}
\hline Revista Veja \\
\hline "Ainda sinto o cheiro daquela lama que descia pelo morro. Não consegui dormir desde \\
então" (19/01/2011) \\
\hline "Todo mundo diz que a culpa não foi nossa. Mas, se tivéssemos chegado antes, teria dado \\
tempo", diz Marcello. Outra lembrança o assombra. "Tenho quase certeza de que ouvi o bebê \\
chorar, mas antes de procurá-lo resgatei uma senhora e os três filhos dela. Depois disso, não \\
ouvi mais o choro. Não cheguei a segurá-lo no colo nem uma vez sequer", conta ele, aos \\
prantos. (23/02/2011) \\
\hline "Minha vontade, às vezes, é desistir de tudo. Sumir. Acordo de madrugada, lembro de tudo o \\
que passamos juntos e começo a chorar. Minha filha fazia tudo para mim: cortava meu cabelo, \\
fazia minha barba. Acho que ela não tinha ideia do quanto eu a amava." (23/02/2011) \\
\hline "Quando me dou conta do que aconteceu, entro em desespero, mas lavo o rosto e tento seguir \\
em frente", diz Carolina. [...] “. Perderam minha mãe, que era tudo para eles, vizinhos e a \\
referência geográfica. Minha avó chora dia e noite. Ela não escuta muito bem e se culpa por \\
não ter acordado durante a chuva." (23/02/2011) \\
\hline "Minha filha era especial", diz ele, aos prantos, enquanto é amparado por parentes. [...] \\
"Sobrevivi para fazer o bem, ajudar as pessoas. Caso contrário, teria sido levado também." \\
(23/02/2011) \\
\hline "Tomo calmantes, mas acordo de madrugada e fico sozinho, em silêncio, esperando o dia \\
\hline
\end{tabular}


amanhecer. Sinto muita saudade de todos, mas saber que isso não aconteceu só com a gente me conforta." (23/02/2011)

"Eu só tinha um buraquinho para respirar. O cachorro da vizinha ouviu meus gritos e começou a latir. Foi quando me encontraram" diz a menina. (23/02/2011)

"Durante esse período, fiquei em estado de choque. Não conseguia falar, comer nem chorar. Quando ela melhorou e voltamos a Friburgo, entrei em desespero.", diz Ronilda. [...] $(23 / 02 / 2011)$

Aqui, somos só eu, a Pretinha e Deus" - Pretinha é a cadela abandonada que ele adotou após a catástrofe. [...] "É muita tristeza. Não consigo comer nem dormir." (23/02/2011)

O discurso jornalístico privilegia, na fala das fontes testemunhais, trechos em que aparecem verbos como sentir, desistir, sumir, chorar ou sobreviver. Ou então, estados emocionais como "aos prantos", "em desespero" ou "triste". Percebe-se que os testemunhos baseiam-se sobretudo na representação da sensação bruta, do concreto, do imediato, do instrumental, e não operam com a explicação e o distanciamento dos fatos. A experiência é imputada sempre ao indivíduo e não a uma coletividade.

Entretanto, essa vivência é representada como a fonte do sentido, como se fosse independente do discurso (HARTLEY, 2001: 106). É como se o leitor estivesse ali, junto com a vítima, sentindo o que ela sente, colocando-se no lugar dela.

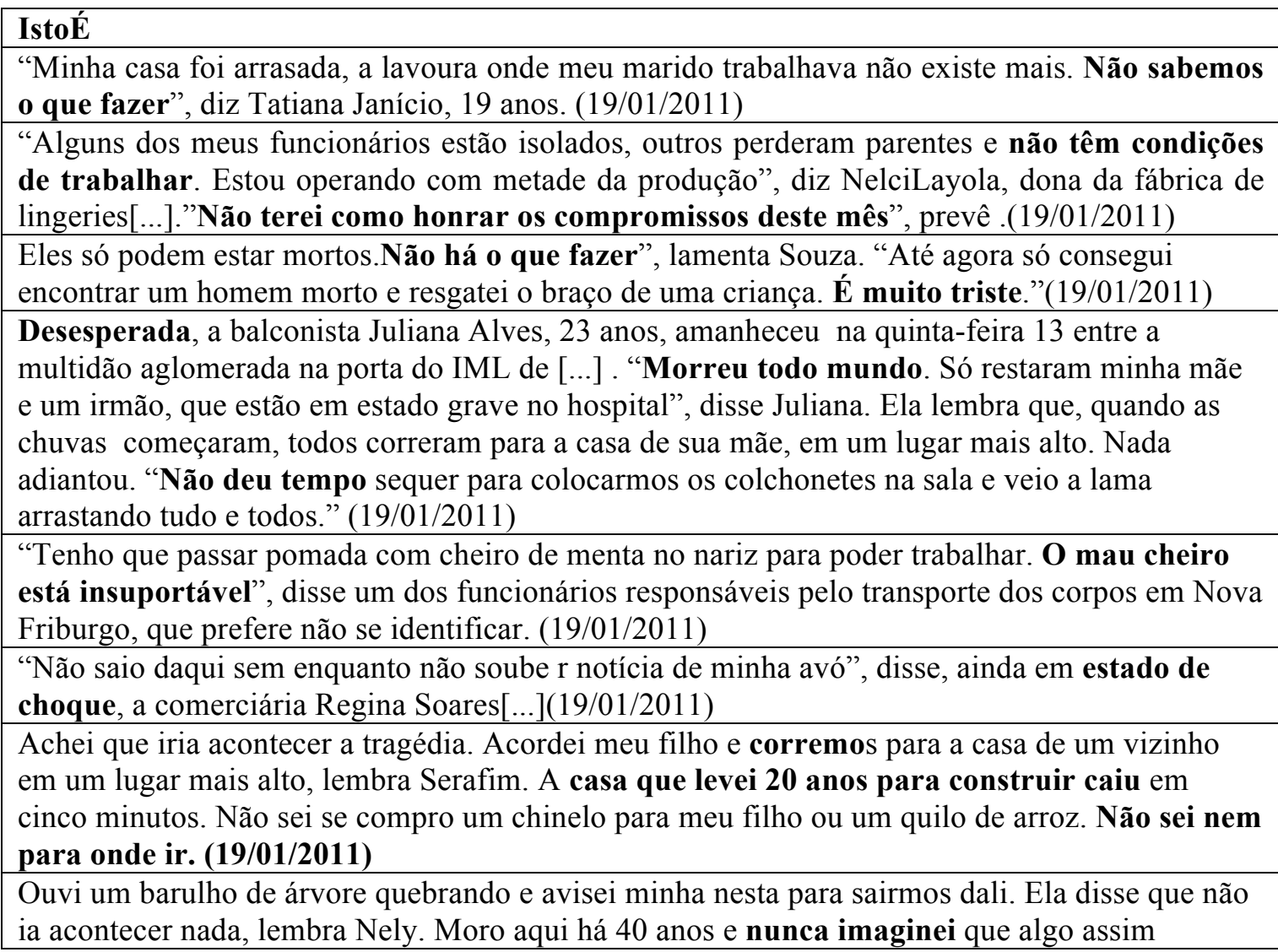


pudesse ocorrer. Perdi minha casa, minha família e minha felicidade, diz Nely. Só restou uma parede azul, nem tenho mais fotografias. (19/01/2011)

Não sei para onde vou, mas para lá não volto mais, prometeu, (19/01/2011)

Perdi minha casa e meu carro no desabamento, contou. Agora, o que eu quero é sair daqui.

$(19 / 01 / 2011)$

Ao analisarmos o papel de cada citação a partir do valor de seu dito (CHARAUDEAU, 2006: 168), observamos também o papel das testemunhas na descrição dos fatos. Charaudeau, ao se referir ao valor das citações, considera efeito de decisão quando a declaração vem de um locutor que tem o poder de decidir, ou seja, tem efeito performativo, pois é declaração ao mesmo tempo em que é a realização de uma ação. O efeito de saber vem de um locutor que tem autoridade pelo saber, envolve as análises e as explicações. O efeito de opinião ocorre quando a declaração vem de um locutor que julga ou aprecia um fato, pode envolver avaliações. Os efeitos de decisão, de saber e de opinião são, na cobertura das revistas analisadas, próprios das fontes autorizadas e experts. Mas há ainda o efeito de testemunho, que emana de um locutor que descreve o que viu ou ouviu. Como diz Charaudeau (2006: 169), "a declaração relatada se reveste de um caráter de veracidade por ter como única finalidade descrever a realidade tal como foi vista e ouvida". Esse é o papel da fontes testemunhais. Optamos neste trabalho por designar esse último efeito de descrição e veracidade para que o termo testemunho, central nesta pesquisa, possa ter um caráter mais amplo. Assim, no discurso midiático, cabe aos testemunhos sobretudo descrever como tudo aconteceu desde seu ponto de vista individual, o que inclui o relato de sentimentos como o medo e a angústia.

\section{Época}

Richard Davidson, de 25, despertou com gritos dos vizinhos. "De repente, tudo começou a tremer debaixo de meus pés", diz. 17/01/2011

Márcio Lopes, de 30 anos, acordou com o estrondo e foi até a janela. [...] "De repente começaram a descer pedra, madeira e muitas pessoas levadas pela correnteza", diz Márcio. 17/01/2011

Assim que começou a clarear, outro morador, Marco Antônio Siqueira, saiu do bairro da Posse em direção a Campo Grande. "Vi corpos na calçada, presos em galhos de árvores que a enxurrada trouxe, em todos os lugares", diz. 17/01/2011

"A gente só fazia rezar para a água não levar a casa", disse Joaci.”Eu só estava preocupado que não enchesse mais, porque eu teria de deixar meu irmão para trás", afirma Joaci, que interrompe a entrevista para chorar. "Sempre que penso nisso, na decisão que eu teria de tomar... Seria impossível de levá-lo comigo", diz. 17/01/2011

$\mathrm{O}$ avô do menino, Ademilson Guimarães, chorou e agradeceu a Deus pelo milagre.

"Agradeço a Deus, não estou acreditando", disse. 17/01/2011 
No caso da dona de casa Illai Pereira de Souza, de 53 anos, o resgate foi feito no braço.

[...]"Pensei que ia morrer. Pedi a Deus que não me deixassem ali", disse ela17/01/2011

Nas matérias analisadas, o medo e a angústia são traduzidos na descrição da experiência mais sensível. Os sentidos do medo são relatados pessoalmente, assim como os sofrimentos mencionados. Não há coletividade, não há poder público, não há revolta contra ninguém nem contra a natureza. Só uma lamentação e o sentimento de impotência frente ao que não é suportável.

Embora os relatos isolados das testemunhas remetam a situações individuais, eles não integram o discurso jornalístico como tais, mas tem efeitos que os transcendem. Participam das matérias jornalísticas para compor uma rede discursiva que constrói os sentidos das catástrofes e que partilha saberes, valores e crenças ligados a acontecimentos trágicos. Remetem tanto a uma maneira de compreender a tragédia, própria de nossos tempos, a partir do relato das testemunhas, quanto a uma maneira de a mídia construir as catástrofes e mobilizar seus leitores.

Assim, tratamos dos efeitos visados pelo discurso jornalístico e não pela manifestação individual de suas fontes. E são apenas efeitos visados, já que somente estudos de recepção dariam conta desse resultado integralmente. Não analisamos o que os sujeitos efetivamente sentem. Assim, o medo e a angústia, neste trabalho, não devem ser considerados como aquilo que o sujeito manifesta por meio de sua fisiologia, nem a situação na qual ele se encontra (sozinho diante uma tragédia). Como ensina Charaudeau (2010: 25), o medo é um discurso socialmente codificado.

O conceito que nos permite este tratamento é de pathos. Os efeitos patêmicos não são da ordem da fala da fonte, do locutor, mas sim da ordem da enunciação midiática (CHARAUDEAU e MAINGUENEAU, 2004: 372). O pathos, que significa um transbordamento emocional, conforme Lausberg (in CHARAUDEAU e MAINGUENEAU, 2004: 371) se exprime por meio de regras práticas que produzem a emoção no auditório. A primeira regra é o "mostre-se emocionado", em que o orador se coloca ou finge estar no estado emocional que deseja transmitir. Ele propõe ao auditório um modelo de emoção que desencadeie empatia. As emoções são autenticadas por várias figuras, como exclamação, interjeição e interrogações. A segunda regra é "mostre objetos", como a casa destruída ou a lágrima da mãe.A terceira regra é "descreva coisas 
emocionantes", ou seja, torne emocionante as coisas indiferentes e descreva as coisas de modo exasperante. As três regras podem ser observadas nas matérias analisadas.

Charaudeau parte de três pontos que considera consensuais entre sociólogos, psicólogos sociais e filosóficos: "as emoções são de ordem intencional, estão ligadas a saberes de crença e se inscrevem em uma problemática da representação psicossocial" (2010: 26). Isso quer dizer que as emoções não podem ser reduzidas à ordem do sensível ou do irracional. Elas se manifestam “em um sujeito 'a propósito` de algo que ele representa para si" (2010: 28), por isso são intencionais. Estão ligadas aos saberes de crença porque se opõem a um saber de conhecimento. Para Charaudeau (apud CHARAUDEAU e MAINGUENEAU 2004: 189), as emoções inserem-se nos saberes de crença.Assim, no relato jornalístico, a emoção do medo não se limita à emoção vista pelo ponto de vista da psicologia ou da sociologia. O discurso midiático tem características que elevam a manifestação do medo e da angústia a outros patamares, transformando-os em visadas específicas.

As emoções são de ordem afetiva, mas vêm também de um imaginário sociodiscursivo, são sancionadas pelas normais sociais. Para Charaudeau, a análise do discurso não tem meios de estudar a emoção vivenciada por alguém, mas sim o processo discursivo em que é inserida, ou seja, "tratá-la como um efeito visado (ou suposto), sem nunca ter a garantia sobre o efeito produzido". Por isso, a preferência pela expressão "efeito patêmico", em detrimento do conceito de emoção. Além do mais, "Não há relação de causa e efeito direto entre exprimir ou descrever uma emoção e provocar um estado emocional no outro" (CHARAUDEAU, 2010: 34).

As crenças não se baseiam em critérios de verdade externos ao sujeito, mas sim em valores socialmente compartilhados. Tratam-se de representações sociodiscursivas, ou seja, "são como mininarrativas que descrevem seres e cenas de vida, fragmentos narrados[...] do mundo que revelam sempre o ponto de vista de um sujeito. Esses enunciados circulam na comunidade social criando uma vasta rede de intertextos" (2010: 32) que se reagrupam num imaginário sociodiscursivo. Um imaginário que busca o efeito de despertar em seus leitores um efeito de vítima virtual.

Há palavras que descrevem emoções como "medo", mas o seu emprego não quer dizer que a pessoa que a utiliza realmente sente medo, nem que ela produzirá um efeito 
patêmico no interlocutor (o que o autor chama de problema de autenticidade). Há outras palavras que não descrevem emoções mas as desencadeiam, nos levam a um "universo patêmico", como catástrofe ou assassinato. No entanto, a orientação argumentativa das palavras pode se modificar quando, por exemplo, mencionamos o assassinato de um tirano. E há enunciados que só produzem efeitos patêmicos, desde que conheçamos a "situação de enunciação" (2010: 39), quando, por exemplo, ouvimos um "meu filho" da boca de um pai em frente ao filho morto. Ou seja, "o efeito de patemização depende das circunstâncias e da situação social e sociocultural na qual se inscreve a troca comunicativa" (2010: 37).

Por isso, o autor aponta como fundamental conhecermos as condições do contrato de comunicação em que a enunciação se situa. "O contrato de comunicação é a primeira sobredeterminação do sentido de discurso". Referindo-se ao dispositivo da comunicação televisiva, Charaudeau lembra de características de cada polo no contrato. Cabe ao polo da fonte de informação a verdade de autenticidade. Também não podemos esquecer que o polo da instância midiática vive numa dupla lógica: mostrar a realidade e dar garantias de autenticidade e objetividade (2010: 41) e, ao mesmo tempo, sobreviver numa concorrência mercadológica. Ao polo da instância de recepção, cabe crer e sentir. A presença de emoções como a angústia e o medo no discurso jornalístico está permeada por todas essas lógicas.

Nos espetáculos que envolvem sofrimento, a instância midiática precisa se colocar como "enunciador que não se envolve" (profissionalismo) e ao mesmo tempo dar "sinais de emoção" (CHARAUDEAU, 2010: 44). A referencialidade é "garantia do efeito de patemização": preciso saber que o sofrimento é realmente vivido "para que eu possa me sentir emocionalmente concernido" (2010: 45). Se for abordar as causas ou culpados, utiliza-se de testemunhos externos. Dessa maneira, o discurso dos testemunhos predispõe efeitos patêmicos e a instância de enunciação se utiliza, no caso da cobertura das catástrofes, de uma encenação discursiva patemizante.

Fernandes (2010: 141) considera o pathos, ou seja, a emoção, como uma condição necessária ao discurso jornalístico, constitutiva dele. No caso da cobertura de catástrofes, a afirmação é conclusiva no que tange ao relato do medo: 
a argumentação patêmica tenta levar o interlocutor a construir hierarquias (maior, menor, mais justo, menos justo), a estabelecer lugares-comuns de quantidade (tudo, nada, alguns, nenhum, eventualmente) e qualidade, a enaltecer os sacrifícios e a entender os sentidos pretendidos por analogias e metáforas. Ou seja, as emoções, de um modo geral, sequem regras racionais de acionamento, com causas e consequências mais ou menos bem definidas. As marcas linguísticas e culturais da emoção podem, então, ser reconstruídas e analisadas. (FERNANDES, 2010: 143)

Para Matheus (2011), o acionamento das sensações é uma característica comum das narrativas jornalísticas, mas o jornalismo não seria capaz de gerar autônoma e automaticamente o medo sem que para isso houvesse condições simbólicas, construídas na longa duração da História.

Embora a análise das sequências discursivas sobre a angústia e o medo retiradas da fala das fontes testemunhais não seja suficiente para analisar uma argumentação patêmica, pois as matérias teriam que ser analisadas na íntegra, a pesquisa nos aponta para futuras investigações neste sentido.

As manifestações das testemunhas sugerem que se tratam de experiências individuais e singulares. Entretanto, o medo e a angústia manifestados partem de valores e sentimentos já partilhados anteriormente sobre o que significa a morte, a falta de moradia, a ausência de perspectiva, o pânico de ver um deslizamento, entre outros.

As coberturas como as realizadas no caso dos mineiros no Chile, dos frequentes deslizamentos no Brasil ou do terremoto e tsunami no Japão viabilizam um tom de espetáculo e, consequentemente, de grande audiência e de altos índices de leitura por parte das empresas jornalísticas. Instigadas por essas informações, à maioria das pessoas cabe assistir minuto a minuto, conhecer amplamente o perfil de cada vítima, acompanhar cada suspiro dos testemunhos (os que se salvaram) e, sobretudo, se transformar em vítimas virtuais. Como afirma Bauman (2008: 10), há o medo efetivo das vítimas e testemunhas dos acontecimentos e o medo derivável, o sentimento de estar suscetível gerado na população em geral, que por vezes é "desacoplado" dos perigos que o causam. Os efeitos patêmicos nos explicam como que aquilo que parece não ter mediação é constitutivo de um discurso que deixa vestígios não somente da compreensão hegemônica sobre os sentidos de uma catástrofe, mas também sobre os sentidos do jornalismo na contemporaneidade que extrapolam em muito o "fazer saber". 
Entre o medo da testemunha e a identificação do leitor com este medo, há muito mais do que emoções individuais - há efeitos patêmicos que integram um contrato de comunicação e, portanto, ofertam determinadas posições de leitura para o relato das catástrofes.

\section{Referências bibliográficas}

BAUMANN, Zygmunt. Medo Líquido. Rio de Janeiro: Zahar, 2008.

BOURDIEU, Pierre. A Economia das Trocas Lingüísticas: O que falar quer dizer. 2. ed. São Paulo: Editora da Universidade de São Paulo, 1998.

CHARAUDEAU, Patrick. Patemização na televisão como estratégia de autenticidade. In: MENDES, Emília e MACHADO, Ida (org.), As emoções no discurso. Mercado Letras, Campinas (SP), 2007.

Discurso das Mídias. São Paulo, Contexto: 2006.

CHARAUDEAU, Patrick e MAINGUENEAU, Dominique. Pathos. In: CHARAUDEAU, Patrick e MAINGUENEAU, Dominique. Dicionário de Análise do Discurso. São Paulo: Contexto, 2004. p.371-372

CHARAUDEAU, Patrick e MAINGUENEAU, Dominique. Emoção. In: CHARAUDEAU, Patrick e MAINGUENEAU, Dominique. Dicionário de Análise do Discurso. São Paulo: Contexto, 2004. p.185-189.

DELUMEAU, Jean. História do medo no ocidente: 1300 -1800 uma cidade sitiada. São Paulo: Cia das Letras.

FERNANDES, Adélia. A emoção no discurso jornalístico: contar histórias e comover leitores. In: MENDES, Emília e MACHADO, Ida (org.), As emoções no discurso. Mercado Letras, Campinas (SP), 2007.

GOMES, Mayra. Jornalismo e ciências da linguagem. São Paulo: Hacker /EDUSP, 2000.

HARTLEY, John. Experiência. In: O'SULLIVAN, Tim et alii. Conceitos-chave em estudos de comunicação e cultura. Piracicaba: UNIMEP, 2001.p. 139.

LAGE, Nilson. A reportagem: teoria e técnica de entrevista e pesquisa jornalística. Rio de Janeiro: Record, 2001.

LOZANO ASCENCIO, Carlos Lozano. La expresión/representación de catástrofes a traves de su divulgación científica em los médios de comunicación social (1986-1991).Tesis doctoral, 2004. Madrid. Universidad Complutense de Madrid.

Aportaciones para uma historia del acontecer catastrófico. Disponível em: $<$ http: www.ubi.bocc.pt>. Capturado em 11 dez. 2011 
MATHEUS, Leticia. Narrativas do Medo - o Jornalismo de Sensações Além do Sensacionalismo. Rio de Janeiro: Mauad-X, 2011.

NESTROVSKY, Arthur e SELIGMANN-SILVA, Márcio (orgs). Catástrofe e representação. São Paulo: Escuta, 2000.

PONTE, Cristina. Leituras das Notícias - contributos para uma análise do discurso jornalístico Lisboa, Livros Horizontes, 2004.

RODRIGUES, Adriano Duarte. Comunicação e experiência. 1997. Disponível em <

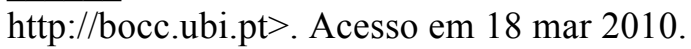

VAZ, Paulo e ROLNY, Gaelle. Políticas do sofrimento e as narrativas midiáticas de catástrofes naturais. In: Anais do XIX Compós, Rio de Janeiro, 2010. 